\title{
Analyzing the Contribution of Crop Diversification in Improving Household Nutrition Security Among Wheat-dominated Rural Households in Sinana District, Bale Zone, Oromia Regional State, Ethiopia.
}

\section{Dereje Derso ( $\boldsymbol{\sim}$ derejso@gmail.com )}

Addis Ababa University https://orcid.org/0000-0003-2435-7939

\section{Degefa Tolossa}

Addis Ababa University College of Development Studies

Abrham Seyoum

Addis Ababa University College of Development Studies

Research article

Keywords: Nutrition security, anthropometry, stunting, wasting, logit model

Posted Date: July 14th, 2021

DOl: https://doi.org/10.21203/rs.3.rs-648539/v1

License: (c) (1) This work is licensed under a Creative Commons Attribution 4.0 International License.

Read Full License 


\section{Analyzing the contribution of Crop diversification in improving household Nutrition Security among wheat-dominated rural households in Sinana District, Bale Zone, Oromia Regional State, Ethiopia.}

Dereje Derso ${ }^{1}$, Degafa Tolossa ${ }^{2}$, Abrham Seyoum ${ }^{3}$

Dereje Derso (PhD Candidate of Development Studies, Center for Rural Development)

Phone No: +251926938212

Degefa Tolossa (PhD, Professor of Geography and Development Studies)

Email: degefatd@gmail.com

Abrham Seyoum (PhD, Assistant professor at College of Development studies, Center for Rural Development)

Email: abrhams3@gmail.com

Abstract

${ }^{1}$ Center for Rural Development, College of Development Studies, Addis Ababa University Ethiopia

${ }^{2}$ Center for Rural Development, College of Development Studies, Addis Ababa University Ethiopia

${ }^{3}$ Center for Rural Development, College of Development Studies, Addis Ababa University Ethiopia 
The long-term impact of malnutrition on people's lives, most notably in health, education, and productivity, highly affects the human capital. Agriculture directly contributes to nutrition security by enabling farm households to access micronutrient food by using their farm income. This study was intended to assess effect of crop diversification on household nutrition security and explores determinants of under-five child malnutrition among rural farm households of Sinana Woreda, Oromia regional state. Multi-stage sampling followed by a systematic random sampling technique was used to include study subjects. Structured questionnaire, focus group discussions (FGDs) and key informant interview was used to collect data. Anthropometric measurements were collected and converted into Z-scores by WHO Anthro version 3.2.2., 2011 software. Then exported to STATA and analyzed using descriptive statistics and inferential statistics. Pearson Correlation coefficients was calculated to see the correlation of the nutrition security status indicators and crop diversification index. Bivariate and multivariate logistic regression was carried out to identify factors associated with child nutrition. The result revealed that the prevalence of malnutrition particularly, stunting was (23.81\%), underweight (21.16\%) and wasting (9.52\%), respectively. The correlation coefficient indicates that crop diversification is negatively correlated with stunting and wasting and positively correlated with underweight and child dietary diversity score. Multivariate logistic regression model indicate that child nutritional status is strongly associated with age of household head, maternal and parental education, farm land size, TLU, availability of potable water, child sex, child dietary diversity, household access to toilet, total annual income, and household access to health services. In conclusion, policy and development interventions should target intensive agricultural production, development of rural infrastructure, education and awareness creation tools to provide households up to date nutritional knowledge and agricultural technologies to increase production and income, and thereby enhance household nutrition security.

Key Words: Nutrition security, anthropometry, stunting, wasting, logit model

\section{Introduction}


Nutritional status in early childhood determines the cognitive development and physical capabilities of a population which threaten the productivity of future generation (Black et al., 2013; Von Braun and Tadesse, 2012; Maluccio et al., 2009). Anthropometric indicators of children are usually used to assess nutrition outcome at early age of life. These indicators include height-forage which shows a long-term nutritional status; weight-for-height that capture short term nutritional outcome; and weight-for-age which is a mixed indicator short- and long-term nutrition outcome (Kalkuhl et al., 2013; Pangaribowo et al., 2013; Smith et al., 2005).

Children are the most visible victims of undernutrition. Global chronic under nutrition in children is highly prevalent and remains a big challenge. The United Nations Food and Agriculture Organization estimates that about 805 million people of the 7.3 billion people within the world, or one in nine, were affected by chronic undernourishment in 2012-2014. Almost all the hungry people, 791 million, sleep in developing countries, representing 13.5 percent, or one in eight, of the population of developing counties. There are 11 million people undernourished in developed countries (FAO, 2014). According to this report 214 million (23.8\%) of all the hungry people of the world are found in sub-Saharan African countries (www.worldhunger.org).

Hunger and malnutrition are devastating problems, particularly for the poor and unprivileged countries like Ethiopia. About 29.9 percent of the total populations of Ethiopia (30.4\% in rural and $25.7 \%$ in urban areas) are found to be under the poverty line. The poor nutritional status of children continues to be a serious problem in Ethiopia. According to 2019 EDHS mini report nationally, about $37 \%, 21 \%$ and $7 \%$ of all children under 5 in Ethiopia were stunted, underweight and wasted respectively. The problem is even worse in rural areas. For instance, the prevalence of underweight and stunting among rural children was $23 \%$ and $41 \%$ compared with only $14 \%$ and $26 \%$ among urban children, respectively. In Oromia region prevalence of child malnutrition indicated that $29.1 \%$ was underweight with $6.6 \%$ severe underweight, $14.1 \%$ of the children are wasted $(3.5 \%$ severe wasting) and $53.6 \%$ of the children are stunted with $17.1 \%$ severe stunting (EDHS, 2016). The long-term impact of malnutrition on people's lives, most notably in health, education, and productivity, highly affects the human capital. For example, an estimated loss of 4.7 billion US\$ (equivalent to $16.5 \%$ of the national GDP) was recorded in 2009 due to child undernutrition in Ethiopia (EPHI, 2013). Therefore, the government of Ethiopia has been following different approaches to scale back maternal and childhood undernutrition significantly. Recently, the 
"Seqota" Declaration (2015-2030) was launched with the goal of eliminating all forms of malnutrition among children under age 2 by 2030 (FDRE, 2016). However, this cannot be achieved unless the production pattern, socio-cultural and religious issues related with feeding practices are deeply investigated and addressed in Ethiopia.

Headey et al., (2012) assessed the role of agriculture in achieving nutrition status. Agriculture directly contributes to nutrition security by enabling farm households to access micronutrient food by using their farm income. In addition to achieving food security, income from farm might improve access to health facilities and healthy environment, which are significant ingredients to achieve nutrition security. This relationship works the other way around as well (FAO et al., 2012). Nutritionally secured households perform better in their farm that increases their return from agriculture. FAO et al. (2012) underlined that small holder agricultural growth is the key to the undernutrition problem as it can increase employment and improve access to food especially for women smallholders. However, the agricultural growth should be "nutrition sensitive" in the sense that it should improve access to health services, drinking water and sanitation. Headey et al. (2012) also implied that agriculture should be viewed as one of the multiple nutrition strategies as nutrition is the outcome of different dimensions including education, health and intrahousehold resource allocation. Bhagowalia et al. (2012) evaluated the association between nutrition, household income and agricultural production using the 2004/05 India Human Development Survey. They explored that the impact of income, unless it is accompanied by better access to health and sanitation facilities and education, has minimal impact on nutritional status of children measured by anthropometric indicators.

Even though the problem of child malnutrition in Ethiopia has been sufficiently documented, the reasons behind it are still poorly understood. There is also inconsistency across studies regarding the determinant factors behind child nutrition. The researcher shares the idea and the main reason behind the need to study contribution of crop diversification on nutritional status in study area is, so far, there are not detailed studies conducted to explore contribution of crop diversification on nutritional status in study area. While most studies on nutrition of both children and adults look into the effects of nutrient consumption and food availability, few studies focus on the relationship between nutritional status and non-nutritional factors, like production patterns, educational attainment, availability of water and sanitation, etc. The objective of this study therefore is to 
measure the effect of crop diversification on household nutrition security and identify determinant factors influencing child malnutrition among rural farm households of Sinana Woreda Bale Zone, Oromia Regional state, Ethiopia.

Materials and Methods 


\section{Sinana Woreda Setting}

The study was conducted in Sinana District which is located in the Bale zone (Figure 1). It is bounded with Goro and Ginir in East, Dinsho in West, Agarfa and Gasera in North and Goba and Barbare Oreda in the south. Astronomically Sinana District lies between $6^{0} 55^{\prime} 00^{\prime \prime}$ to $7^{0} 18^{\prime} 00$ North and $39^{\circ} 53^{\prime} 00^{\prime \prime}$ to $40^{\circ} 26^{\prime} 00^{\prime \prime}$ 'East.

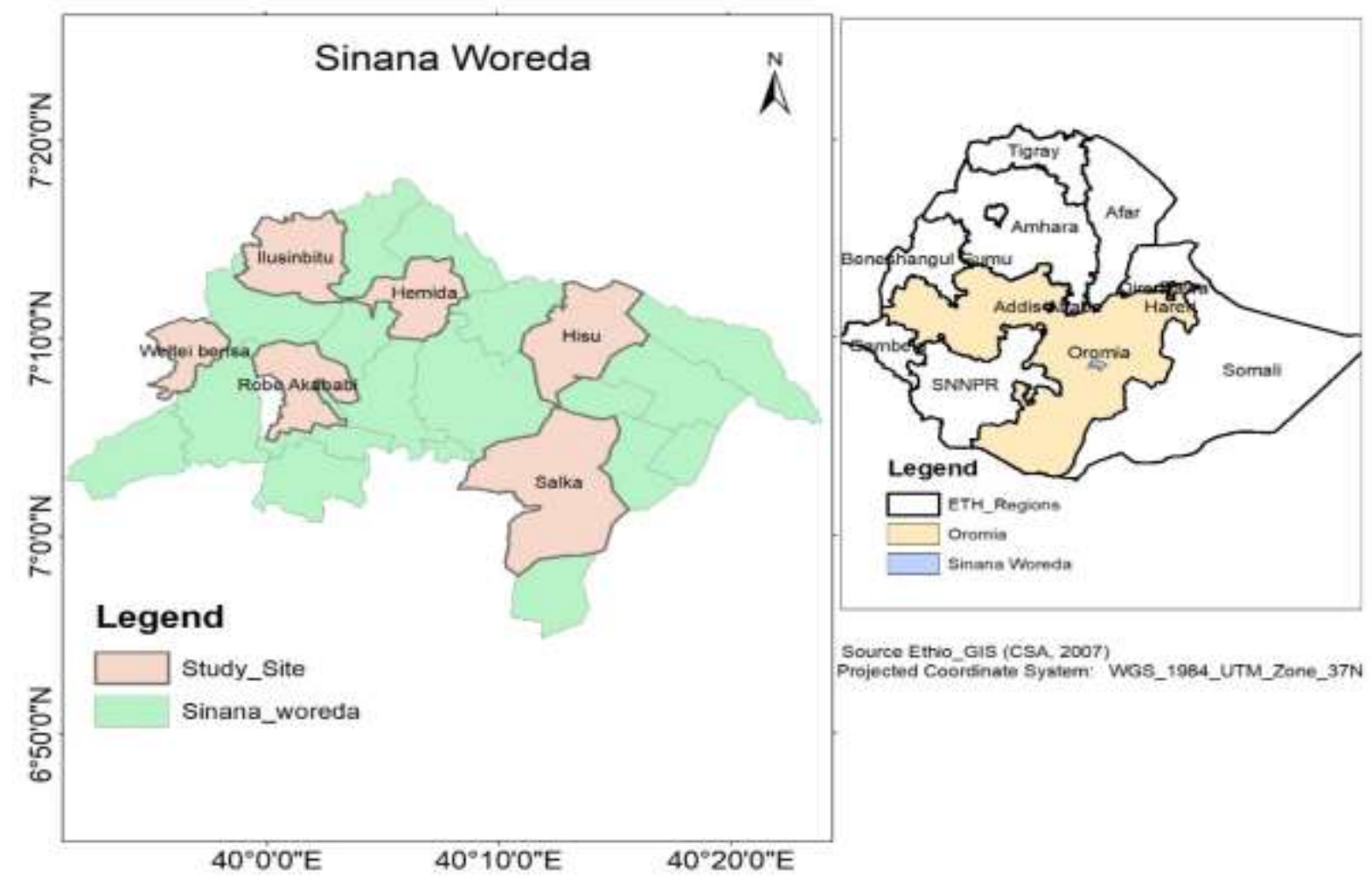

Figure 1: Location of the study in Oromia Region.

\section{Study Design}

Cross-sectional design was employed to gather relevant and sufficient information. The study design was used quantitative and qualitative research approach to assess the effect of crop diversification on household nutrition and determinants of child malnutrition in Sinana Woreda of Bale Zone; from May 21 to June 21, 2019.

\section{Data sources}


Both primary and secondary data were collected for this study. The primary data was collected using structured questionnaire from eligible respondents (mother or caregiver of index child) and anthropometric measurement. Whereas, secondary data were collected from available document at Bale Zone and Sinana Woreda Health Office, catchment Health Center and Health post.

\section{Sample Size Determination}

To determine the children to be included in the study different methods were employed in order to get representative sample size. A multi stage sampling technique was used to select sampled households. In the first stage, one Wereda was selected randomly from nine highland Waredas of Bale Zone. In the second stage based on simple random sampling technique six Kebeles from Sinana Woreda were selected. To obtain a representative sample size, the study employed the sample size determination formula given by Yamane (1967):

$$
\mathrm{n}=\frac{\mathrm{N}}{1+\mathrm{N}\left(\mathrm{e}^{2}\right)}=\frac{9768}{1+9768\left(0.05^{2}\right)}=\frac{9768}{25.42}=384
$$

Where $\mathrm{n}$ is the sample size, $\mathrm{N}$ is the population size (total households in the six kebeles which is 9768) and $e$ is the level of precision. Finally, based on random sampling techniques all 6-59 months of children in selected household were included in this study.

\section{Data Collection Methods and Instruments}

Quantitative data was collected using a structured questionnaire. The questionnaire was translated and contextualized to the local situation. Data on sociodemographic factors were collected by interviewing mother or caregiver of index child. Anthropometric measurement was collected. A structured questionnaire was used to collect data on the child dietary diversity. Qualitative data were collected through focus group discussions (FGDs) to complement the quantitative data so as to identify factors affecting child nutrition. FGD participants were selected purposely among selected sample households in each selected kebele. Seven guiding questions were asked for each session. There were 7-9 women participants in each group; a total of 105 participants in 13 groups.

\section{Empirical Model and Data Analysis}


The quantitative data collected through structured questionnaire was entered in to STATA 14.2 for analysis. To convert the anthropometric data into Z-scores of the indices WHO Anthro version 3.2.2, 2011 software was used for stunting HAZ (Height for Age Z-score), underweight WAZ (Weight for Age Z-score) and wasting WHZ (Weight for Height Z-score) and exported to STATA 14.2 for further analysis. Descriptive statistics such as frequency, percentage, mean and standard deviation was used to organize distribution of child demographic, household's demographic and socioeconomic, maternal and caring behavior and environmental characteristics. Pearson's correlation coefficients were used first to analyze the role of crop diversification on household nutrition. Bivariate and multivariate logit regression model used to estimate the determinants that influence child malnutrition in study area.

\section{Specification of logistic model}

In this study, anthropometric data was converted into weight-for-age Z-scores (WAZ), height-forage Z-scores (HAZ) and weight-for-height Z-scores (WHZ) in relation to the (WHO, 2006) reference population. More specifically, Z-score for an individual $i$ will be calculated using the following equation:

$$
\text { Z-Score } \frac{X_{i}-X_{r}}{\delta_{r}}
$$

Where $X_{i}=$ an observed value for $i^{\text {th }}$ child in a target population

$X_{r}=$ a median of the reference population; and

$\delta_{r}=$ a standard deviation (SD) of the reference population

A Z-score of -2 standard deviation is the most commonly adopted cut-off point for all nutrition indicators. Consequently, in this study, a child with Z-scores below -2 SD in respective nutrition status indicators will be considered to be malnourished. Clearly, stunted ( $-2 \delta$ HAZ), underweight $(-2 \delta \mathrm{WAZ})$ or wasted $(-2 \delta \mathrm{WHZ})$.

Thus, the probability that a child's nutritional status is normal, which is indicated through HAZ, WAZ, WHA, can be specified using the following equation (Gujarati, 1995):

$$
\mathrm{P}(\mathrm{Mi}=1 / \mathrm{k})=\frac{1}{1+e^{-\left(a_{0}+a_{1} k_{1}\right)}}
$$


Where, $k$ is a vector of explanatory variables influencing nutritional outcomes; $e$ is the base of natural logarithm; $a_{s}$ are regression coefficients to be estimated; and $i$ indexes individual children below the age of five.

\section{Data Diagnostics and Estimation Procedure}

Before estimating the econometric models, assessments were made on the data to make sure that the data meets some basic statistical assumptions. In particular, the study applied Variance Inflation Factor (VIF) procedure to test the presence of multicollinearity among the explanatory variables of models. The VIF test for each explanatory variable $\left(\mathrm{X}_{i}\right)$ is applied based on the following formula:

Tolerance $=1-\mathrm{R}^{2}$ where $\mathrm{R}^{2}$ is the coefficient of determination for the regression of that variable on all remaining independent variables.

$$
\operatorname{VIF}(\mathrm{X} i)=\frac{1}{1-R^{2}}
$$

Where, $R^{2}$ is the coefficient of determination when $\mathrm{X} i$ is regressed on the remaining explanatory variables of the model. A VIF value greater than 10 is used as a signal for existence of severe multicollinearity (Gujarati, 1995). To minimize potential heteroscedasticity due to interdependent observations, the standard errors of the model coefficients were estimated using robust standard errors with clustering at household level. 


\section{Definition of Variables and Working Hypothesis}

In Table 1, we identify the main explanatory variables along with their anticipated impact on the child nutrition status. Our hypotheses on the variables have been guided by economic theory, previous empirical studies and local knowledge on the problems being studied.

Table 1: Summary of Variables included to affect child nutrition status

\begin{tabular}{|c|c|c|c|}
\hline Variables & Variables unit and measurement & & \\
\hline \multicolumn{4}{|c|}{ Dependent Variables } \\
\hline Stunting & HAZ (Height for Age Z-score) & \multicolumn{2}{|l|}{ Binary outcome } \\
\hline Underweight & WAZ (Weight for Age Z-score) & \multicolumn{2}{|l|}{ Binary outcome } \\
\hline Wasting & WHZ (Weight for Height Z-score) & \multicolumn{2}{|l|}{ Binary outcome } \\
\hline \multicolumn{4}{|c|}{ Explanatory Variables } \\
\hline Age & Age of household head in year & Continuous & $+/-$ \\
\hline Edu & Education level in year of schooling & Continuous & + \\
\hline Hsize & Size of household in number & Continuous & + \\
\hline Cfiveandb & Number of children less than five year & Continuous & + \\
\hline Lsize & Size of farm land in ha & Continuous & $+/-$ \\
\hline Dhealth & Distance to health center in walking minute/hour & Continuous & - \\
\hline Nincome & Total income in birr & Continuous & + \\
\hline TLU & Livestock holding in TLU & Continuous & - \\
\hline Nonfarm & Participation on non-farm activities, yes $=1, \mathrm{No}=0$ & Discrete & $+/-$ \\
\hline Edumoth & Education level of mother in year of schooling & Continuous & - \\
\hline Csex & Sex of child, $1=$ Male, $0=$ Female & Discrete & $+/-$ \\
\hline Cage & Age of child in year & Continuous & $+/-$ \\
\hline Elecricity & Access to electricity, $\mathrm{Yes}=1, \mathrm{No}=0$ & Discrete & - \\
\hline cleanW & Access to clean water, $\mathrm{Yes}=1, \mathrm{No}=0$ & Discrete & - \\
\hline Toilet & Access to toilet, $\mathrm{Yes}=1, \mathrm{No}=0$ & Discrete & - \\
\hline Morbidity & $\begin{array}{l}\text { Incidence of morbidity (like diarrhea, fever and } \\
\text { cough) } \mathrm{Yes}=1, \mathrm{No}_{0}=0\end{array}$ & & + \\
\hline Healthacc & Access to health services, $\mathrm{Yes}=1, \mathrm{No}=0$ & Discrete & - \\
\hline CDI & Crop diversification index & Continuous & - \\
\hline CDD & Child Dietary Diversity, count of consumed food & Continuous & - \\
\hline
\end{tabular}




\section{Result and Discussion}

\section{Households and Children Characteristics}

Descriptive analysis of data regarding age of the household head shows that sample household heads' age ranged from 25 to 67 years with mean of 40.89 years. About $90.48 \%$ of the sample households were male-headed and the remaining (9.52\%) were female-headed. Out of the 189 children in the sample households, $52.91 \%$ were male, while $47.09 \%$ were female. About $77.25 \%$ and $55.03 \%$ of the fathers and mothers have never attended formal education, respectively. With regard to the marital status of the sample respondents, $92.59 \%$ were married, $5.29 \%$ were widowed and the remaining $(2.12 \%)$ were divorced. The majority of the respondents $(80.32 \%)$ were Muslims and $15.43 \%$ orthodox respectively and the rest were protestant.

Clean water and toilet facilities are indicators of healthy environment which may improve child health and nutrition. Hence, according to the survey, about $38.10 \%$ of the sample households were using clean water/ protected water. In response to the question regarding the use of latrine, the survey result indicates that about $43.39 \%$ of the sample households have latrine exposure.

Table 2: Household characteristics for categorical variables $(n=189)$

\begin{tabular}{llll}
\hline Variables & & Frequency & Percent \\
\hline Gender & Male & 171 & 90.48 \\
Marital status & Female & 18 & 9.52 \\
& Married & 175 & 92.59 \\
Child sex & Widowed & 10 & 5.29 \\
& Divorced & 4 & 2.12 \\
Religion & Male & 100 & 52.91 \\
& Female & 89 & 47.09 \\
& Muslim & 151 & 80.32 \\
Potable water & Orthodox & 29 & 15.43 \\
& Protestant & 8 & 4.26 \\
Toilet & Yes & 72 & 38.10 \\
& No & 117 & 61.90 \\
Electricity & Yes & 82 & 43.39 \\
& No & 107 & 56.61 \\
Access to health services & Yes & 49 & 25.93 \\
& No & 140 & 74.07 \\
Morbidity & Yes & 134 & 70.90 \\
& No & 55 & 29.10 \\
& Yes & 170 & 89.95 \\
& No & 10 & 10.05 \\
\hline
\end{tabular}


The average family size of the sample households is found to be about 7.0 persons. The mean age of children was approximately 26 months and the minimum and maximum age of the sample children is 11 and 59 months. Concerning number of children less than five year in the household the average children less than five year was 1.2 and the maximum children less than five year in the household was 3.

In the study area livestock are used for different purposes. Cattle are used especially for milk and meat, source of income and as drought power. Equines are used for transportation; sheep and goat are also source of income. The households also obtain income from the sale of animal products such as eggs, cheese, butter, and milk. In the study areas, the average total livestock unit (TLU) of the study households was 7.38 with 4.46 standard deviation. Concerning household annual income, the average household annual income was 5208.47. The average child dietary diversity was 3.62 with minimum and maximum of 2 and 6 food group consumed respectively.

Table 3:Household characteristics for continuous Variables $(n=189)$

\begin{tabular}{lll}
\hline Variables & Mean & SD \\
\hline Age of household head & 40.90 & 10.44 \\
Household size & 7.01 & 2.56 \\
Number of children less than five yea & 1.20 & 0.47 \\
Education level of household head & 0.49 & 0.94 \\
Education level of mother & 1.40 & 1.83 \\
Age of children & 2.14 & 1.00 \\
Total annual income & 5208.47 & 2303.57 \\
Livestock holding in TLU & 7.38 & 4.46 \\
Child dietary diversity & 3.62 & 1.05 \\
\hline
\end{tabular}

\section{Prevalence of Malnutrition}

Better nutritional status of children reflects a healthy and a productive generation in future. In particular for preschool children, it is a critical factor for optimum growth and it should be neither inadequate nor excessive manner. It is widely believed and scientifically proved that improved nutrition and health enhance the learning ability of the children. In the long run, it leads to an increase in the strength of the labour force and thereby it contributes positively for the economic growth. 
In the present study, the results for the extent of child nutrition status are presented using three common anthropometric indicators: height-for-age (HAZ), weight-for-age (WAZ), and weightfor-height (WHZ) Z-scores. The Z-scores were derived using the reference standards. As noted earlier, standard cut-off points and definitions are used for malnutrition.

A summary statistic of nutritional status of children in the study area reveals that the prevalence of stunting ( $<-2 \mathrm{HAZ})$, underweight $(<-2 \mathrm{WAZ})$ and wasting. Analysis of the results shows that the level of stunting, underweight and wasting in children in study area were $23.81 \%, 21.16 \%$ and $9.52 \%$ respectively. The prevalence of stunting in study area is found to be high for female children $(60.00 \%)$ than male children. Further, the finding indicates that prevalence of underweight and wasting in study area is found to be high for male children (57.5\% and 66.67\%) respectively.

Table 4:Prevalence of stunting, underweight and wasting

\begin{tabular}{lccc}
\hline Gender Group & Stunted & Underweight & Wasted \\
\hline Male & $18(40.00)$ & $23(57.5)$ & $12(66.67)$ \\
Female & $27(60.00)$ & $17(42.5)$ & $6(33.33)$ \\
Combined & $45(23.81)$ & $40(21.16)$ & $18(9.52)$ \\
\hline
\end{tabular}

\section{Effect of Crop Diversification on household Nutrition}

This sub-section presents the relationship among the household nutrition status and crop diversification with respect to the sample households. Pearson Correlation coefficients was calculated to see the correlation of the Nutrition security status indicators (HAZ, WAZ, WHZ and DDS) and crop diversification index (CDI). Table 5 gives the overview of the Pearson's correlation coefficients for the continuous variables.

Table 5:Pearson Correlation coefficients for the continuous variables

\begin{tabular}{llllll}
\hline & CDI & HAZ & WAZ & WHZ & CDDS \\
\hline CDI & 1.00 & & & & \\
HAZ & -0.0055 & 1.00 & & & \\
WAZ & 0.0761 & -0.1984 & 1.00 & & \\
WHZ & -0.0175 & 0.0725 & -0.0357 & 1.00 & \\
CDDS & 0.0653 & -0.1266 & -0.1551 & -0.2167 & 1.00 \\
\hline
\end{tabular}

The finding indicates that, CDI score is negatively correlated with $\mathrm{HAZ}$ and WHZ and positively correlated with WAZ and CDDS. As the nutrition status increases, HAZ and WHZ decreases. 
Negative association between CDI and HAZ and WHZ means that Crop diversification increases household nutrition security. Further higher CDI means higher crop diversification and higher CDDS scores indicate better nutrition status of the households. However, the correlations between crop diversification index and nutrition indicators were not significant and the correlation between child dietary diversity and nutrition indicators were significant at less than 0.01 . Using correlation analysis, it was examined that the DDS score is negatively correlated with nutrition indicators.

\section{Determinants of Child Nutrition}

\section{Bivariate analysis}

The bivariate analysis (crude analysis) was conducted to find out the independent effect of each explanatory variable on the binary outcome variables. It helps to identify potential variables for the multivariate analysis. The variables associated at $10 \%$ level of significance were taken into account in order to not exclude potential determinants from the analysis at early stage. Binary logistic regression indicates that education level of household head, distance to health center, total annual income, mother education, and access to electricity were found statistically significant predictors of stunting in the bivariate analysis. Further, age of household head, education level of household head, number of children less than five year, farm land size, TLU, access to potable water, availability of toilet and access to health service were significantly affecting underweight in the bivariate analysis. On the other hand, age of household head, household size, number of children less than five years, participation on non-farm activities, mother education, child sex, access to health services and child dietary diversity were significantly affecting wasting in the bivariate analysis (Table 6). 
Table 6:Bivariate logistic regression estimates for child malnutrition

\begin{tabular}{|c|c|c|c|c|c|c|}
\hline \multirow[t]{2}{*}{ Explanatory variables } & \multicolumn{2}{|c|}{ Stunting (HAZ) } & \multicolumn{2}{|c|}{ Underweight (WAZ) } & \multicolumn{2}{|c|}{ Wasting (WHZ) } \\
\hline & M.eff & Std.err & M.eff & Std.err & M.eff & St.err \\
\hline Age of household head & 0.002 & 0.030 & -0.011 & $0.063 *$ & -0.007 & $0.054 * *$ \\
\hline Education of household head & 0.060 & $0.363 * *$ & -0.056 & $0.524 * * *$ & 0.022 & 0.396 \\
\hline Household size & 0.014 & 0.140 & -0.010 & 0.188 & 0.029 & $0.219 * *$ \\
\hline Children less than five year & -0.036 & 0.726 & 0.093 & $0.919 * * *$ & -0.131 & $0.966 * *$ \\
\hline Farm land size & -0.017 & 0.227 & 0.051 & $0.287 *$ & 0.003 & 0.218 \\
\hline Distance to health & 0.006 & $0.038 * * *$ & -0.002 & 0.048 & -0.003 & 0.044 \\
\hline Total annual income & -0.279 & 0.908 & 0.029 & 0.485 & 0.033 & 0.482 \\
\hline TLU & 0.002 & 0.074 & -0.020 & $0.138 * *$ & -0.002 & 0.078 \\
\hline Participating on non/off-farm & -0.047 & 0.701 & -0.058 & 0.954 & -0.102 & $0.889 * * *$ \\
\hline Education of mother & -0.244 & $1.016^{*}$ & 0.016 & 0.212 & -0.028 & $0.233 * * *$ \\
\hline Child sex & -0.048 & 0.568 & 0.001 & 0.740 & 0.105 & $0.769 * *$ \\
\hline Child age & -0.028 & 0.298 & 0.009 & 0.364 & 0.019 & 0.321 \\
\hline Access to Electricity & -0.088 & $0.684 * * *$ & -0.051 & 0.865 & -0.068 & 0.877 \\
\hline Access to potable water & 0.052 & 0.792 & -0.182 & $1.371 * *$ & -0.079 & 0.956 \\
\hline Availability of Toilet & 0.032 & 0.762 & 0.101 & $1.047 * * *$ & 0.075 & 0.863 \\
\hline Morbidity & 0.181 & $0.093 * *$ & -0.108 & 0.076 & 0.155 & $0.072 * *$ \\
\hline Access to health services & 0.003 & 0.628 & -0.315 & $1.062 *$ & 0.216 & $1.377 * *$ \\
\hline Crop diversification index & 0.084 & 1.125 & 0.020 & 1.348 & 0.002 & 1.266 \\
\hline Child dietary diversity & -0.006 & 0.134 & -0.003 & 0.152 & -0.022 & $0.181 * *$ \\
\hline _cons & & 2.249 & & 3.510 & & 2.787 \\
\hline Number of observations & \multicolumn{2}{|l|}{188} & \multicolumn{2}{|l|}{188} & \multicolumn{2}{|l|}{188} \\
\hline Correctly predict & \multicolumn{2}{|l|}{58.99} & \multicolumn{2}{|l|}{64.14} & \multicolumn{2}{|l|}{34.94} \\
\hline Model Chi-square $\chi^{2(22)}$ & \multicolumn{2}{|l|}{122.06} & \multicolumn{2}{|c|}{$\chi^{2(18)}=124.82$} & \multicolumn{2}{|c|}{$\chi^{2(18)}=41.47$} \\
\hline
\end{tabular}

$*, * *$, and $* * *$ indicate statistical significance at 1,5 , and $10 \%$ probability levels, respectively: M.eff $=$ marginal effect, St.er $=$ standard error

\section{Multivariate logistic regression analysis}

Multivariate logistic regression analysis was conducted to identify the independent predictor variables that affect child malnutrition. All significant explanatory variables included in the bivariate analysis were analyzed in the multivariate model to find out the imperative determinants of child malnutrition (Table 7).

Maternal and father educational status is one of the most determinants of child nutritional status (Turyashemererwa et al., 2009). This might be due to educated mothers and fathers were more aware of their children nutritional consequence than illiterate parents. Illiterate parents may less likely to introduce new feeding practice, which helps to improve the nutritional status of their children. This study found that maternal and father education were found to be statistically significant factor that determines stunting and wasting. The negative value shows that a child 
whose mother had formal education has less probability to be stunted and wasted compared to a child whose mother did not attended formal education. The marginal effect shows other things being constant, the likelihood of child being stunted and wasted decrease by $1.6 \%$ and $2.2 \%$ respectively as education level of mother increase by one year. Likewise, the probability of the child being WAZ and WHZ decreases by $0.9 \%$ and $0.4 \%$, respectively, as education level of household head increases by year. The fact that mother education level was significant is in agreement with different studies under taken on the same problem. For instance, studies done in Ethiopia, Bangladesh, and Nigeria (Sebanjo et al. 2009, Mengistu et al. 2013, Dasgupta et al. 2014) confirm this finding. This is because educated mothers are more conscious about their children's health and they tend to look after their children in a better way. Moreover, literate mothers can easily introduce new feeding practices scientifically, which help to improve their children nutritional status (Das et al. 2008).

The coefficient associated with household income is found to be negative and significant determinant of child nutrition indicator HAZ. In brief, children from household with high income are less stunted than those with low income, ceteris paribus. Specifically, the marginal effect shows that, the probability of the child to be stunted will be decreased by $18.9 \%$ with one birr increase in household income. This finding is consistent with other studies (Girma and Genebo, 2002; Kandala et al. 2010). The study indicated that better off households had better access to food and higher cash incomes than poor households, allowing them a quality diet, better access to medical care and more money to spend on essential non-food items such as schooling, clothing and hygiene products.

The women discussants reached consensus with the idea, "As far as money is there, it is possible to buy everything and diversify our child diet even though the market is so far." (FGD)

The coefficient associated with farm land size, could be worth mentioning; similar to our anticipation, this variable is found to be negative and significant determinant of child nutrition indicator, WAZ. In brief, children from household with large farm land size are less underweight than those with small farm land size, ceteris paribus. Specifically, the probability of the child to be normal in WAZ, will decrease by $5.9 \%$, with one hectare increase in cultivated farmland. Similar study by Fentaw et al., (2013), and Saaka and Osman, (2013) found that land size 
significantly and positively associated with improved dietary diversity and food access, which is extremely important to improve the nutritional status of children.

Multivariate logit regression model result reveals that, TLU is significant at $(p<0.1)$ probability level and influences negatively underweight. The negative relationship is explained by the fact that livestock size being a proxy for rural household resource endowment, those sample respondents with large livestock size have better chance to earn more income. Other things remain constant; the marginal effect of the model shows, having large size of livestock decrease probability of underweight by $1.0 \%$. The significances of TLU on underweight could be from a direct consumption of what they own or through increased purchasing ability of the households as they generate income from owning livestock. This finding is similar with Taruvinga et al., (2013), Belachew et al. (2013) indicating that livestock are sources for several food groups (eggs, meat, and goat milk) that may provide micro and macronutrients and largely contributes for household nutrition.

The women discussants reached consensus with the idea, "Since we usually produce crops on our farm and we can't produce all types of foods. Men farmers interested in producing wheat only. Sometimes we rely on market for child diet. Currently it's very difficult to get livestock output like milk, meat and others in most households. Although that is possible to get milk and butter from the market distance of market makes food exchange very difficult, especially for elders, pregnant women, and mothers with children." (FGD)

The findings of this study indicate that incidence of morbidity (like diarrhea, fever and cough) for the last two weeks before the survey is a contributing factor to the prevalence of malnutrition. The variables (WAZ and WHZ) are found to be negative and significant $(<0.05)$. The marginal effect of the variable indicates that the probability of the child to become stunting and wasting will increase by $10.5 \%$ and $14.9 \%$ respectively if he/she is morbid for the last two weeks. There may be two justifications for this effect. One is bearing in mind that wasting is a picture of current or acute malnutrition, morbidity can contribute to a failure to gain weight or actual weight loss. Another can be wasting from childhood diseases are more likely because of reduced appetite, less quantity of fluids and foods offered during their sickness. It is also known that malnourished children will have frequent diarrheal episodes and lose weight and can quickly become 
malnourished (CSA et al., 2011). This result was consistent with finding of other studies (Ajao et al., 2010, Bealu et al., 2017).

Another noteworthy finding of this study is the negative and significant relationship of the availability of electricity, clean water and toilet to child nutrition status measured by HAZ and WAZ respectively. The variable Electricity negatively and significantly affected HAZ at ten percent significant level. The marginal effect value depicted that, the probability of the child to be stunted will be decreased by about $9.6 \%$ if there is electricity in the household. Further, availability of clean water to household negatively and significantly affected child nutrition measured by WAZ at one percent significant level. From the model result, the marginal effect reveals that the likelihoods of underweight decreased by $17.9 \%$ if household has access to clean water in study area. This is supported by study done in Amhara region northwest Ethiopia and rural Ethiopia (Bantamen et al., 2014; Alemu, 2013). In the rural population of Ethiopia, there is lack access of safe drinking water is the major environmental problems for the transmission of common diseases. Lack of access to safe drinking water and unprotected drinking water is closely related to incidence or episode of water borne diseases like diarrhea which contribute malnutrition. In addition to this lack of access to drinking water (it estimated that more than two thirds of the population have no access to drinking water) is a direct cause of malnutrition (Kandala et al., 2011). This is also consistent to the study done in Tigray, Ethiopia, which revealed, using unprotected sources of water in the household of children were 2 times more likely under nutrition as compared with those who consumed protected water (Alemayehu et al. 2014).

FGDs held with women's group indicated that access to potable water and electricity was the main problem in their village. Despite the ownership of latrines by majority of respondents, however, there was a problem when it comes to the use. FGDs in all the sample kebeles revealed that shortage of water to clean the latrine was bringing bad smell and, as a result, compelled members of households to excrete in unsafe places. A key informant interview held with the head of the Woreda's health office also confirmed the weak usage of latrines due to shortage of water that could be used for cleaning.

Among other important economic variables, access to health services is also found to be significant determinant of the child nutrition status. As expected, the coefficient of the variable is found to be 
negative and statistically significant for underweight. In other words, a child in households who have better access to health services is relatively more wasted than a child in a household with no access to health services, ceteris paribus. The marginal effect of the variable indicates that the probability of the child to be underweighted will be decreased by about $54.5 \%$ if household have access to health services.

Sex of the children is important demographic variable. Male children were more likely to be wasted than girls. From the model result, the marginal effect reveals that the likelihoods of wasting increase by $8.0 \%$, for male children comparing with their female counter parts. This study is consistent with the other similar study in Ethiopia; Amhara and Tigray regions (Teshome et al. 2009; Alemayehu et al. 2013) and Inconsistence with study in Oromia Region (Mengistu et al. 2012). This discrepancy might be due to cultural and Environmental similarity and deference. The cause of this discrepancy in sex is not well established in the literature, but it might be due to boy were more exposed or influenced by environmental circumstance than girls.

The coefficient of child dietary diversity is significant at 10 and $5 \%$ and shows a negative and positive impact on child stunting and wasting respectively. The negative influence implies that child with higher child dietary diversity are less malnutrition than low dietary diversity. Marginal effect indicates that, holding other variables in the model constant, the probability of the child to be stunted will be decreased by about $2.2 \% \%$ as food group consumed by children increased by one. In contrast to priori hypothesis the coefficients of wasting are positive indicating that children with higher child dietary wasted than child with lower child dietary diversity, ceteris paribus. In particular, the marginal effect shows that, the probability of the child to be wasted, will increase by $1.9 \%$, as food group consumed by children increased by one. These findings advance support to findings of previous studies (Taruvinga et al.,2013; M'Kaibi et al., 2016). 
Table 7:Multivariate logistic regression estimates for child malnutrition

\begin{tabular}{lllllll}
\hline Explanatory variables & \multicolumn{2}{l}{ Stunting (HAZ) } & \multicolumn{2}{l}{ Underweight (WAZ) } & \multicolumn{2}{l}{ Wasting (WHZ) } \\
\cline { 2 - 7 } & M.eff & Std.err & M.eff & St.er & M.eff & St.err \\
Age of household head & 0.005 & $0.003^{* * *}$ & -0.009 & $0.002^{*}$ & -0.004 & $0.002^{* * *}$ \\
Education of household head & 0.055 & $0.032^{* * *}$ & -0.021 & 0.026 & 0.026 & 0.025 \\
Household size & 0.014 & 0.014 & -0.010 & 0.011 & 0.015 & 0.011 \\
Children less than five year & -0.026 & 0.065 & 0.087 & 0.053 & -0.083 & 0.051 \\
Farm land size & -0.013 & 0.019 & 0.059 & $0.016^{*}$ & 0.008 & 0.015 \\
Distance to health & 0.006 & 0.004 & -0.001 & 0.003 & -0.001 & 0.003 \\
Total annual income & -0.189 & $0.039^{*}$ & -0.012 & 0.031 & 0.020 & 0.030 \\
TLU & 0.002 & 0.007 & -0.010 & $0.006^{* * *}$ & 0.000 & 0.005 \\
Participating on non/off-farm & 0.014 & 0.062 & -0.059 & 0.051 & -0.077 & 0.049 \\
Education of mother & -0.078 & $0.016^{*}$ & 0.021 & 0.013 & -0.022 & $0.012^{* * *}$ \\
Child sex & -0.060 & 0.056 & -0.016 & 0.046 & 0.080 & $0.044^{* * *}$ \\
Access to Electricity & -0.057 & 0.066 & -0.096 & $0.054^{* * *}$ & -0.012 & 0.052 \\
Access to potable water & 0.119 & 0.081 & -0.179 & $0.066^{*}$ & -0.132 & $0.064^{* *}$ \\
Availability of Toilet & 0.007 & 0.075 & 0.155 & $0.061^{* *}$ & 0.134 & $0.059^{* *}$ \\
Morbidity & -0.179 & $0.091^{* *}$ & 0.105 & 0.075 & -0.149 & $0.713^{* *}$ \\
Access to health services & 0.082 & 0.060 & -0.545 & $0.049 *$ & 0.129 & $0.047^{*}$ \\
Child dietary diversity & -0.022 & $0.012^{* * *}$ & 0.008 & 0.010 & 0.019 & $0.009^{* *}$ \\
cons & & 0.200 & & 0.163 & & 0.156 \\
\hline
\end{tabular}

$*, * *$, and $* * *$ indicate statistical significance at 1,5 , and $10 \%$ probability levels, respectively: M.eff $=$ marginal effect, St.er $=$ standard error 


\section{Conclusions and Recommendations}

In this study, we mainly investigated the relationship between crop diversification and nutrition security in sinana Woreda using cross-sectional survey collected in 2019. In addition, we analyzed the determinants of child malnutrition level using bivariate and multivariate estimation techniques.

The study demonstrated that crop diversification enhances household nutrition security. Analysis of the results shows that the level of stunting, underweight and wasting of children in study area were $23.81 \%, 21.16 \%$ and $9.52 \%$ respectively. The prevalence of stunting in study area is found to be high for female children $(60.00 \%)$ than male children.

The bivariate analysis indicates that child stunting was affected by education level of household head, distance to health center, total annual income, mother education, and access to electricity. Further, age of household head, education level of household head, number of children less than five year, farm land size, TLU, access to potable water, availability of toilet and access to health service were significantly affecting underweight in the bivariate analysis. It is also indicated that age of household head, household size, number of children less than five years, participation on non/off-farm activities, mother education, child sex, access to health services and child dietary diversity were significantly affecting wasting in the bivariate analysis. On the other hand, multivariate analysis revealed that various intermediate factors like age of household head, education level of household head and mother, farm land size, total annual income, TLU, sex of children, access to electricity, potable water, toilet, health services, morbidity prior to data collections, and child dietary diversity were found to influence household nutrition security.

Based on the findings of the study, we recommend that the regional and federal governments should provide access to education for households to broaden their understanding of the nutritional health benefits of a diverse diet and Sinana Agricultural and Natural Resources Office and stakeholders in the agricultural sector should promote and encourage availability of intensive agricultural practices, introduce agricultural technologies to boost income of rural households and thus diversify their diet. 
Sticking to the findings of this study, access to health services which implies the contribution made by income was found significant and substantial in achieving nutrition security. This implies that efforts have to be made to improve income from crops production and non/off-farm activities to ensure nutrition security through promotion of input use and marketing facilities. Further, Market and health infrastructure should be improved to enhance households' access to market and health that could contribute for improving household nutrition.

Livestock sub sector plays a great role in the struggle to eliminate child malnutrition. Its contribution to the child dietary diversity is significant. Hence, necessary effort should be made to improve the production and productivity of the sector. This can be done through the supply of adequate veterinary services, improved water system points, introduction of timely and effective artificial insemination services to up-grade the already existing breeds, launching sustainable and effective forage development program, provision of coaching for the livestock holders on the way to improve their production and productivity and improving the marketing conditions.

\section{Ethics approval and consent to participate}

The researchers have obtained a support letter from Addis Ababa University. The letter was submitted to Bale Zone Agriculture and Natural Resource Office and obtained consent. Then, the zonal offices have written an official letter to Sinana District Agriculture and Natural Resource Office where the study was conducted. Informed consents were also obtained from the households, discussants, and informants before data collection in conformity with anonymity of the study participants.

\section{Consent for publication}

Not applicable

\section{Availability of data and materials}

The authors want to declare that they can submit the data at whatever time based on your request. The datasets used and/or analyzed during the current study will be available from the corresponding author on reasonable request.

\section{Competing interests}

The authors declare they have no competing interests. 


\section{Funding}

This research was supported and funding by Addis Ababa University.

\section{Authors' contributions}

Dereje Derso designed the study, collected the data, performed the analysis, and developed the manuscript. DT and AS contributed to the research design and analysis, reviewed and made editorial comments on the draft manuscript. All authors read and approved the final manuscript.

\section{Acknowledgements}

The authors acknowledge respondent farmers and data collectors. Addis Ababa University, Madda Walabu University were also acknowledged for their financial and logistical support in accomplishing this paper. The authors also would like to extend their deep thanks to all the contributors of this study, namely local administrators, and development agent workers who took part in the survey.

\section{Abbreviations}

Agricultural Development Led Industrialization: ADLI; Bale Zone Agriculture Development Organization: BZADO; Bale Zone Finance and Economic Development: BZFED; Crop Diversification Index: CDI; Focus Group Discussions: FGDs; Gross Domestic Product: GDP; Growth and Transformation Plans: GTPs; HAZ: Height for Age Z-score; Herfindahl Index: HI; Inverse Mill's Ratio: IMR; Key Informant Interviews: KIIs; Ordinary Least Square: OLS; Tropical Livestock Unit: TLU; WAZ: Weight for Age Z-score; WHZ: Weight for Height Z-score 


\section{References}

Alemayehu M, Tinsae F, Haileslassie K, Seid O, G/egziabher G, Yebyo H. 2013. Nutritional status and associated factors among under-five children, Tigray, Northern Ethiopia. International Journal of Nutrition and Food Sciences.

Alemayehu M, Tinsae F, Haileslassie K. 2014. Nutritional status and associated factors among under-five children, Tigray, Northern Ethiopia. Int J Nutr Food Sci 2014; 3: 6.

Alemu F. 2013. Assessment of the impact of malnutrition on children at Dilla referral hospital and unity pediatric clinic, Ethiopia. Int J Nutr Metab; 5: 105-113.

Bantamen G, Belaynew W, Dube J. 2014. Assessment of factors associated with malnutrition among under-five years age children at Machakel Woreda, Northwest Ethiopia: A case control study. Nutr Food Sci 2014; 4:1.

Bealu B., Tekle E., Fissahaye A.,and Desalegn M. (2017). Household Food Insecurity and Its Association with Nutritional Status of Children 6-59 Months of Age in East Badawacho District, South Ethiopia. Journal of Environmental and Public Health: Volume 2017, Article ID 6373595, 17 pages https://doi.org/10.1155/2017/6373595

Belachew T., Tessema M., Ersino G. 2013. Feeding patterns and stunting during early childhood in rural communities of Sidama, South Ethiopia. Pan African Medical Journal - ISSN: 1937- 8688 (www.panafrican-med-journal.com) Published in partnership with the African Field Epidemiology Network (AFENET). (www.afenet.net)

Bhagowalia, P; Kadiyala, S; Headey, D; (2012) Agriculture, income and nutrition linkages in India: Insights from a nationally representative survey. Technical Report. The International Food Policy Research Institute, Washington DC. https://researchonline.lshtm.ac.uk/id/eprint/1440436

Birhan Fetene. 2010. Determinants of Nutrition and Health Status of Children in Ethiopia: A Multivariate Multilevel Linear Regression Analysis. Addis Ababa University

Black, R. E., Alderman, H., Bhutta, Z. A., Gillespie, S., Haddad, L., Horton, S., Lartey, A., Mannar, V., Ruel, M., Victora, C. G., Walker, S.P., and Webb, P. 2013. Maternal and child nutrition: building momentum for impact. The Lancet, 382(9890), 372-375.

Das, S., Hossain; M.Z., and Islam, M.A. 2008. Predictors of Child Chronic Malnutrition in Bangladesh. Proc.Pakistan Acad. Sci. 45(3): P.137-155.

Dasgupta, A. Parthasarathi,R. Ram Prabhakar V., Biswas,R. and Geethanjali,A. 2014. "Assessment of under nutrition with composite index of anthropometric failure (CIAF) among under-five children in a rural area of west bengal," Indian Journal of Community Health, vol. 26, no. 2, pp. 132-138.

Ethiopian Public Health Institute (EPHI) Ethiopia and ICF. 2019. Ethiopia Mini Demographic and Health Survey 2019: Key Indicators. Rockville, Maryland, USA: EPHI and ICF. 
FAO, IFAD, WFP. 2012. strengthening the enabling environment for food security and nutrition. Rome: Italy

Federal Democratic Republic of Ethiopia (FDRE) Food and Nutrtion Policy. 2018. Federal Democratic Republic of Ethiopia, Food and Nutrtion Policy, Addis Ababa, Ethiopia.

Federal Democratic Republic of Ethiopia (FDRE). 2013. Ethiopia National Nutrition Programme Implementing Sectors Declaration, "Government of the Federal Democratic Republic of Ethiopia (2013-2015)".

Federal Democratic Republic of Ethiopia (FDRE). 2016. Seqota declaration implementation plan (2016-2030): Summary program approach document. Addis Ababa: Ethiopia.

Fentaw R., Bogale A. and Abebaw D. 2013. Prevalence of child malnutrition in agro-pastoral households in Afar Regional State of Ethiopia. Nutrition Research and Practice (Nutr Res Pract) 2013;7(2):122-131: http://dx.doi.org/10.4162/nrp.2013.7.2.122 pISSN 1976-1457 eISSN 2005 6168

Fikadu. T, Assegid. S, Dube L. 2014. Factors associated with stunting among children of age 24 to 59 months in Meskan district, Gurage Zone, South Ethiopia: a case-control study. BMC Public Health.

Gujarati DN (1995) Basic econometrics. 3rd Edn. McGraw-Hill Inc., New York., ISBN13:9780070252141, p 838

Hien Nn, Hoa nn. 2009. Nutrition status and determinants of malnutrition in children under three years of age in Nghean, Vietnam. Pakistan Journal of nutrition. 2009; 8.

Kalkuhl, M., Kornher, L., Kozicka, M., Boulanger, P., and Torero, M. 2013. Long-Term Drivers of Food and Nutrition Security. FOODSECURE working paper no.06. The Hague: LEI Wageningen UR.

Kandala N, Madungu T, Emina J. 2011. Malnutrition among children under the age of five in the Democratic Republic of Congo (DRC): Does geographic location matter? BMC Public Health 2011; 11:1-15

Kandala, N., Fahrmeir, L. and Klasen, S. 2010. Geo-additive Models of Childhood Undernutrition in Three Sub-Saharan African Countries. Sonderfor

Kravdal Ø. and Kodzi I. 2009. Children's stunting in sub-Saharan Africa: Is there an externality effect of high fertility? Demographic Research. 2011; 25: 18.

M. Saaka and S. M. Osman, "Does household food insecurity affect the nutritional status of preschool children aged 6-36 months?" International Journal of Population Research, vol. 2013, Article ID 304169, 12 pages, 2013.

M. Tesfaye. 2009. "Bayesian approach to identify predictors of children Nutritional status in Ethiopia." 
M'Kaibi FK, Steyn NP, Ochola SA. 2016. The relationship between agricultural biodiversity, dietary diversity, household food security, and stunting of children in rural Kenya. Food Sci Nutr. 2016. DOI:10.1002/fsn3.387

Maluccio, J. A., Hoddinott, J., Behrman, J. R., Martorell, R., Quisumbing, A. R., and Stein, A. D. 2009. The impact of improving nutrition during early childhood on education among Guatemalan adults. The Economic Journal, 119(537), 734-763.

Mekonnen H. 2013. Malnutrition and its Correlates among Rural Primary School Children of Fogera District, Northwest Ethiopia. Nutritional Disorders \& Therapy.

Mengistu K, Alemu K, Destaw B. 2012. Prevalence of Malnutrition and Associated Factors Among Children Aged 6-59 Months at Hidabu Abote District, North Shewa, Oromia Regional State. Nutritional Disorders \& Therapy.

Mengistu K., Alemu K., and Destaw B.2013. "Prevalence of malnutrition and associated factors among children aged 6-59 months at hidabu abote district, north shewa, Oromia regional state," Journal of Nutritional Disorders \& Therapy, vol. T1, article 001, 2013.

Pangaribowo, E. H., Gerber, N., \& Torero, M. 2013. Food and nutrition security indicators: a review. FOODSECURE working paper no. 05, FOODSECURE project, The Hague: LEI Wageningen UR

Rahman, A. and Chowdhury, S. 2007. Determinants of Chronic Malnutrition Among Preschool Children in Bangladesh. Journal of Biosocial Science 39(2) :P.161-173.

Sasha, F. 2009. An Analysis of Under-Five Nutritional Status in Lesotho: The Role of Parity Order and Other Socio-Demographic Characteristics.

Sebanjo I. O., Adeodu, O. O. and Adejuyigbe E. A. 2009. Influence of socio-economic factors on nutritional status of children in a rural community of Osun State, Nigeria, 2009.

Sereebutra, P., Solomons, N., Aliyu, M.H., and Jolly, P.E. 2006. Socio-Demographic and Environmental Predictors of Childhood Stunting in Rural Guatemala. Nutrition Research.

Smith, L. C., Ruel, M. T., and Ndiaye, A. 2005. Why is child malnutrition lower in urban than in rural areas? Evidence from 36 developing countries. World Development, 33(8), 1285-1305.

T. Sebsibe and A. Yinges, "Urban-rural differentials in child undernutrition in Ethiopia," International Journal of Nutrition and Metabolism, vol. 7, no. 1, pp. 15-23, 2015.

Taruvinga A, Muchenje V, Mushunje A. 2013. Determinants of rural household dietary diversity: the case of Amatole and Nyandeni districts. South Africa. Int J Dev Sustainability. 2(4):22332247.

Taruvinga, A., Muchenje, V and Mushunje, A. 2013. Determinants of rural household dietary diversity: The case of Amatole and Nyandeni districts, South Africa. International Journal of Development and Sustainability 2(4): 2233-2247. 
Teshome B, Kogi-Makau W, Getahun Z, Taye G. 2009. Magnitude and determinants of stunting in children underfive years of age in food surplus region of Ethiopia: The case of West Gojam Zone. Ethiop J Health Dev. 23: 98-106.

Turyashemererwa F., Kikafunda J, and E Agaba. 2009. Prevalence of Early Childhood Malnutrition and Influencing Factors in Peri Urban Areas of Kabarole District, Western Uganda. African Journal of Food Agriculture Nutrition and Development. Vol. 9: 975-989

Turyashemererwa, F. Kikafunda, J. Annan, R. and Tumuhimbise, G. A. 2013. Dietary patterns, anthropometric status, prevalence and risk factors for anaemia among school children aged 511 years in Central Uganda. Journal of Human Nutrition and Dietetics, Vol. 26, Issue., p. 73.

Von Braun, J., and Tadesse, G. 2012. Global food price volatility and spikes: an overview of costs, causes, and solutions ZEF-Discussion Papers on Development Policy. Bonn: ZEF.

Woldemariam Girma and Timotiows Genebo 2002. Determinants of Nutritional Status of Women and Children in Ethiopia.

Yamane T. 1967. Statistics, an introductory analysis. 2nd ed. New York: Harper and Row. 